\title{
"Seven Fat Years and Seven Lean Years"? Climate Change and Agriculture in Africa
}

Coleen Vogel

\section{Introduction}

Climate change and variability of climate are currently subject to some debate (e.g. IPCC 2001; Lomborg 2001). Despite the debate between those convinced of the reality of human-induced climate change and those who are contrarians, past impacts of climate variability, including droughts, are real for many in Africa, particularly the rural poor and those seeking an existence from rain-fed agriculture (Sokona and Denton 2001). In semi-arid and arid parts of the continent, crop yields are frequently lowered by decreases in rainfall below the average (e.g. 75 per cent of normal rainfall in parts of Southern Africa), periods of intense rainfall, and variations in temperature and soil moisture (e.g. Mendelsohn et al. 2000). Impacts, during extreme periods as well as during periods of "normal" climate variability affect both irrigated, commercial farmers and related enterprises but also, notably, those depending on rain-fed agriculture. While one may argue that African farmers have adapted to climate variations in the past, others are suggesting (Mendelsohn et al. 2000a and 2000b) that future climate change may force large regions of marginal agriculture out of production in Africa (Devereux and Edwards 2004).

It is against this background that this article addresses climate change and its impacts and implications for Africa. Assessments are briefly reviewed of how climate has and is currently impacting African agriculture, then possible future scenarios for agriculture that may accompany climate change are examined. These projections are then assessed in relation to current and future development contexts. Other multiple stressors, such as HIV/AIDS, governance and conflict are shown to heighten periods of climate stress. Also briefly considered are globalisation, trade, market access and the role of food supply, outlets and access. Finally, possible interventions are suggested.

\section{Agriculture and the current African economy}

Agriculture forms a large part of the economies of several African countries. Most African countries average 21 per cent of gross domestic product (GDP) made up from agriculture; others range between 10-70 per cent. Amoako (2000) and Mendelsohn (2000a) both show that with development this figure can drop. With an optimistic outlook this contribution could shift to as little as 4 per cent by 2100. In the case of Malawi, however, the contribution made by agriculture to GDP has in fact been rising (to more than 40 per cent) as a result of industrial stagnation and the contraction of the public service sector (Benson and Clay 2004). Critical for possible future reductions in the agricultural share of GDP will be diversification in agriculture and a focus on manufacturing (Amoako 2000).

Agriculture is also an important sector in both the formal economy and in sustaining local livelihoods. Agriculture is, however, currently constrained by biophysical and socio-economic problems including land degradation, poor infrastructure and market access, lack of access to information and resources, and insecurities around water often occasioned by poor infrastructure and very often highlighted by periods of climate stress. Experts have thus expressed concern that impacts associated with climate change may be particularly severe for many African countries (IPCC 2001).

IDS Bulletin Vol 36 No 2 June 2005 @ Institute of Development Studies 


\section{Impacts associated with extreme events}

In African countries dependent on agriculture, losses associated with extreme periods of climate stress (e.g. droughts and floods) can result in major impacts on GDP. More pervasive, however, is the impact of climate stress on general well-being, particularly on those dependent on rain-fed agriculture. Several countries in Southern Africa showed marked contractions in GDP with droughts in 1991/92, except where economies were dominated by other sectors (e.g. Namibia and Botswana strongly supported by the mineral exports) (Benson and Clay 2004). Large contractions in GDP are only one indicator of impact. More pervasive consequences of climate stress include losses in farm labour opportunities and general loss of livelihoods.

The ENSO (El Niño Southern Oscillation) has been shown to be strongly linked to rainfall variability in several parts of the continent (e.g. Richard et al. 2001; Jury 1995; Lindesay 1988). ${ }^{1}$ Occasionally ENSO has been associated with severe droughts - for instance, in the early 1980s and 1990s, particularly in Southern Africa. During these periods there were marked impacts on cereals such as maize. The extreme drought in 1991/2, for example, is estimated to have reduced maize production by 10 million metric tons, with costs of US $\$ 500 \mathrm{mn}$ in logistical costs of importing cereals into affected countries in Southern Africa (Benson and Clay 2004). 'There were also severe wider impacts on GDP and the agricultural sector of at least double this magnitude over 12 months' (Benson and Clay 2004: 93).

Flooding also impacts several sectors including agriculture, devastating livelihoods. For example, the floods in East Africa (1998) and the floods from tropical cyclones in Mozambique (2000) caused considerable damage to property and infrastructure, reduced Mozambique's annual growth rate from 8 to 2 per cent (Washington et al. 2004), and displaced 2 million people (IPCC 2001). Infrastructural damage and communications among settlements meant that refugees could not be reached by land. Such devastating impacts, as witnessed on a much larger scale with the recent Asian tsunami, are not easily overcome, and much-needed developmentfinance is often diverted to be spent on short- and long-term relief and recovery.
While there is no conclusive evidence that ENSO-associated droughts are increasing (Washington et al. 2004) some argue that there is a likelihood that extreme events such as droughts and floods may become stronger and more frequent in the future: 'More important than the mean rainfall changes are the possible increases in the number and intensity of extreme rainfall events' (Mason and Joubert 1997; cited in Bridgman 1998: 276; see also Fischer et al. 2002).

\section{Future scenarios of climate change and agriculture using various models}

All too often, the focus in climate change and extreme climate events focuses narrowly on the biophysical causes and impacts of such changes within certain spatial and temporal frames - the "big events". The recent food crisis in Southern Africa, however, has shown that while drought did indeed contribute to the crisis in Zimbabwe, Zambia and Malawi, in other parts of the region, for example, Lesotho, severe hail and frosts also contributed to food shortages. Both the "extreme changes" in climate and the "variability" around the "norm" or normal are thus receiving much attention: 'A combination of slow climatic changes and increasing frequency of sudden shocks could trigger much larger and more frequent harvest collapses than countries can cope with' (Devereux and Edwards 2004: 4).

Impacts associated with climate change for agriculture are therefore not only those associated with extreme or marked periods of climate variation (e.g. a drought or a run of very dry years). Literature on agriculture and climate change is, for example, focused on the role of increased temperature associated with global warming. While this is a very complex science still facing areas of uncertainty, increases in temperature and carbon dioxide are, for example, linked to plant growth through higher rates of photosynthesis being favoured by increases in carbon dioxide (Cesar et al. 2004). Such linkages have spurred on much research into the relationships between climate variables, such as temperature and rainfall, and agriculture as well as research and modelling on climate circulation, atmospheric gases and global warming. Some of these advances in climate science and agriculture are provided below.

Early assessments of these linkages, using various 
outputs from a number of Global Circulation Models (GCMs), have shown that agricultural areas of Africa could be vulnerable to changes in climate (e.g. Rosenzweig and Hillel 1998). Parts of subSaharan Africa (e.g. Zimbabwe) were noted as being vulnerable to climate change. In other parts of the continent sea-level rise may enhance coastal erosion along the shores of the Sakha Delta. Model estimates also show crop production could be reduced. Using a specific climate change scenario, 'Crop modeling simulations with GCM climate change scenarios at the high end of the (the Inter-governmental Panel on Climate Change) IPCC range $\left(\sim 4^{\circ} \mathrm{C}\right)$ project that maize and wheat yields may decline in the Delta (Sakha) by as much as 30\% and in middle Egypt (Giza) by more than 50\%' (Rosenzweig and Hillel 1998: 209).

Later assessments, such as those citied in the IPCC (2001), refer to the Zimbabwean case (cited by Rosenzweig and Hillel 1998) and also outline possible impacts on livestock production. Complex links between temperature, rainfall, soil quality and grasses have been described. Tree growth in savannas, for example, is linked to soils, moisture and also to fire activity. If fire intensity were to decrease, in association with an increase of dryseason rainfall, then woody cover would increase bringing with it impacts for livestock in parts of Africa. An increase, for example, of $1-2^{\circ} \mathrm{C}^{\prime} \ldots$ would make the montane grasslands (highveld) of Southern Africa susceptible to invasion by savanna trees' (IPCC 2001, citing Ellery et al. 1991). Recent assessments of global warming and various species show that extinctions of between 15-37 per cent of certain species may occur in parts of Africa and elsewhere (Thomas et al. 2004).

Other assessments and scenarios for parts of Southern Africa - a region set to be particularly vulnerable to climate changes - indicate future warming across Africa ranging from $0.2^{\circ} \mathrm{C}$ per decade (low scenario) to more than $0.5^{\circ} \mathrm{C}$ per decade (high scenario) (Hulme et al. 2001). Additionally, there is a general consensus that rainfall may increase in East Africa and drying out may occur in parts of southwest Africa (SafMa 2004).

Mendelsohn et al. (2000a), citing initial cases that use 14 alternative climate models, outline the impacts of climate change on agriculture for several countries in Africa. Seven countries in Africa, for example, were shown to suffer largest losses in the agricultural sector (in descending order: Nigeria,
Sudan, Algeria, Cameroon, South Africa, Morocco, Zaire). These countries comprise about 47 per cent of possible damages to agriculture. If one then assesses the impacts as a fraction of GDP, then the countries most impacted are: Zambia, Niger, Chad, Burkina Faso, Togo, Botswana, Guinea Bissau and Gambia (in descending order). With these simulated results Mendelsohn et al. (2000a: 7) conclude:

As of today there is sufficient evidence to conclude that African agriculture is very vulnerable to climate change. The modeling results presented here indicate that the potential damages may be large both in absolute terms and as a fraction of agricultural GDP.

Finally, one of the most comprehensive attempts to assess climate change and global agricultural vulnerability is that by Fischer et al. (2002). The sensitivity of agro-ecosystems, as determined by the International Institute for Applied Systems Analysis' FAO/IIASA Agro-ecological Zones (AEZ) model, was examined with reference to the socioeconomic scenarios defined by the IPCC Special Report on Emissions (Parry 2002) and the Basic Linked System (BLS). Using a combination of AEZ and BLS, an integrated ecological-economic framework for assessments of climate change was provided. Using GCM projections, some areas showed gains in agricultural land but in the case of Africa, decreases were recorded with "substantial losses" predicted for sub-Saharan Africa (Fischer et al. 2002: 73). The impacts on food security are thus marked:

With the exception of the results for the NCARPCM model, Sudan, Nigeria, Senegal, Mali, Burkina Faso, Somalia, Ethiopia, Zimbabwe, Chad, Sierra Leone, Angola, Mozambique, and Niger lose cereal production potential in the 2080s ... These countries currently have 87 million undernourished, equivalent to $45 \%$ of the total undernourished in sub-Saharan Africa. (Fischer et al. 2002: 90)

Despite the various types of GCM data used and various complex interactions and feedbacks it would seem that, in most cases, the outlooks for Africa and agriculture are negative. Areas of marked variability, however, are often concealed in these larger aggregations and simulations. Even if some 
initial cases show only apparent small losses in maize production, these cases may be masking the rather larger losses in rural livelihoods and food insecurity that may still be experienced in other areas (Jones and Thornton 2003). Whatever the case, such outlooks are concerning because it is in Africa where most of the vulnerable are already located and whose capacities are already strained (Sachs 2005).

\section{Linkages between climate change and other change stressors}

Climate change and its consequences do not occur in a vacuum; very often they merely unveil an already precarious and vulnerable situation. Problems of HIV/AIDS, poor governance, land conflict, etc. mean that, for some, small climate changes can have a significant impact. These other stresses made the lesser 2001/3 drought have a perhaps greater impact on livelihoods than the 1991/2 one (FFSSA 2004: 1).

Assessments of climate and agriculture offer clearly focused analyses of biophysical dimensions. But an equally strong, if not stronger case, is now being made for the other "stress" factors or "drivers" of change. Almost all previous assessments and scenarios mention the precarious nature of livelihoods in Africa and the strong linkages between local livelihoods and natural resources (with or without climate change). Several recent assessments in the food crisis in Southern Africa, for example, show that variable climate is only one of the factors driving food insecurity in the region. Escalating impacts of HIV/AIDS, lack of effective trade and market opportunities, problematic governance all further hamper food insecurity:

... the 2001-3 crisis was not precipitated solely by the impact of adverse climatic conditions on maize harvests ... Low stocks were a far more significant factor ... resulting from the combination of the running down of strategic grain reserves ... [T] he interplay of politics in the policy process, market liberalisation as currently implemented, economic coordination failures, and the HIV/AIDS pandemic has contributed to [human vulnerability] ... (FFSSA 2004: 15, 16, parentheses added)

The importance of climatic variability should not be overestimated: it is only one aspect of the vulnerability context. The complex mix of climate (e.g. drought) and other factors have been repeatedly shown to be detrimental for several African countries (Ahmed and Lipton 1997; Ashley and Maxwell 2002; Kanji and Barrientos 2002; Maxwell and Slater 2003). Assessments of the famine in Ethiopia, just like those cited above for Southern Africa, show that a combination of trigger factors and underlying vulnerability factors contributed to heightened food insecurity:

The famine of 2000 occurred because of a combination of trigger factors and underlying vulnerability factors. The main trigger factors were: the severe and protracted drought for three successive years from 1998 to 2000, which caused large-scale livestock mortality and displaced thousands of people ... [and] the late delivery of food aid for a number of technical, logistical and political reasons .... (Devereux 2004: 3)

The agricultural sector is increasingly being shaped by wider "structural" factors including globalisation, international trade regimes and other policy arrangements) (Kanji and Barrientos 2002). Food markets and supermarket outlets, for example, have been shown to be essential nodes shaping the arena in which small-scale agricultural producers need to be connected to in order to survive: 'The rapid development of the supermarket sector in Africa implies that supermarkets already do, and will increasingly, influence the structure and conditions of the agri-food system in Africa' (Weatherspoon and Reardon 2003: 351). Variations in climate, in Southern Africa, may indeed become more marked, extreme and more frequent in future (Mason and Joubert 1997). The interplay between continuing changes in climate, on the one hand, and socio-political and economic issues, on the other, operating at a variety of scales, is thus a critical area requiring much more research in Africa.

\section{Possible interventions to improve adaptation and resilience to change: climate stress}

Climate change plays, and has always played, a major role in configuring local livelihoods and national economies in Africa. Many are concerned, however, that despite past experience and resilience, future changes in extreme climate events and in 
"normal" climate are going to be harsh for Africans. Such changes, moreover, are going to occur in already highly vulnerable contexts (including declining environmental conditions, eroding institutions and changing political circumstances). Adaptive capacity is thus acutely constrained.

Despite the gloomy outlook, however, much can be done to reduce risks to climate stress. Possible interventions, for example, include those linked directly to bolstering and improving climate science and our understanding of the climate systems, impacts and feedbacks for Africa. There is a need for funding to improve our understanding of the basic functioning of climates over Africa, improved modelling capacity, better early warning systems, and improved understanding of the role, value and

\section{Note}

1. See also CLIVAR (Climate Variability and Predictability Programme) Exchanges at www.ifm.uni-kiel/other/ publications

\section{References}

Ahmed, I. and Lipton, M., 1997, 'Impact of structural adjustment on sustainable rural livelihoods: a review of the literature', Working Paper 62, Brighton: Institute of Development Studies

Amoako, K.Y., 2000, 'Economic development and reform issues in Africa: lessons for Ghana', Africa Policy E-Journal, 21 September

Ashley, C. and Maxwell, S., 2001, 'Rethinking rural development', Briefing Paper, London: Overseas Development Institute, March

Benson, C. and Clay, E., 2004, 'Understanding the Economic and Financial Impacts of Natural Disasters', Disaster Risk Management Series No 4, Washington, D.C.: World Bank

Bridgman, H.A., 1998, 'Future climate scenarios for the southern continents', in J.E. Hobbs, J.A. Lindesay and H.A. Bridgman (eds), Climates of the Southern Continents, Present, Past and Future, Chichester: John Wiley and Sons: 276

Cesar, H., Linden, O. and Walker, R., 2004, 'Inventory of research on the impacts of climate change', Interim Report IR-04-018, Laxenburg: International Institute for Applied Systems Analysis

Devereux, S., 2004, 'Food security issues in Ethiopia: comparisons and contrasts between lowland and uptake of forecasts (e.g. O'Brien and Vogel 2003; Washington et al. 2004). Additionally, there is also a great need to understand what generates vulnerabilities and what enhances resilience to changes (including among others, climate stress, macro- and micro-policy political changes), as well as understanding of peoples' livelihoods in both "normal" and "stressed" periods. Finally, there is a need to enhance adaptive capacities to reduce risks to stress (including climate stress) and improve institutional architecture required for such activities (e.g. Ogunseitan 2003). For many African countries, therefore, research and development that couples climate change and the development agenda is a key priority.

highland areas', paper presented at a seminar organised by the Pastoralist Communication Initiative, UN-OCHA, Addis Ababa, 16 February Devereux, S. and Edwards, J., 2004, 'Responding to drought and food insecurity', ID21 Insight 53, www.id21.org (accessed April 2005)

FFSSA, 2004, 'Achieving Food Security in Southern Africa: Policy Issues and Options Synthesis Paper', London: Forum for Food Security in Southern Africa, www.odi.org.uk/ food-securityforum

Fischer, G., Shah, M. and van Velthuizen, H., 2002, Climate Change and Agricultural Vulnerability, Laxenburg: International Institute for Applied Systems Analysis, Laxenburg, Austria

Hulme, M., Doherty, R.M., Ngara, T., New, M.G. and Lister, D., 2001, 'African climate change: 1900-2100', Climate Research, Vol 17: 145-68

Jones, P.G. and Thornton, P.K., 2003, 'The potential impacts of climate change on maize production in Africa and Latin America in 2005', Global Environmental Change 13: 51-9

IPCC (Intergovernmental Panel on Climate Change), McCarthy, J., Canziani, O.F., Leary, N.A., Dokken, D.J. and White, K.S. (eds), 2001, Climate Change 2001: Impacts, Adaptation, and Vulnerability, Cambridge: Cambridge University Press 
Jury, M.R., 1995, 'A review on ocean-atmosphere interactions and South African climate variability', South African Journal Science, Vol 91: 289-94

Kanji, N. and Barrientos, S., 2002, 'Trade liberalisation, poverty and livelihoods: understanding the linkages', Working Paper 159, Brighton: Institute of Development Studies

Lindesay, J.A., 1988, 'Southern African rainfall, the southern oscillation and a Southern Hemisphere semi-annual cycle', Journal of Climatology, Vol 8: $17-30$

Lomborg, B., 2001, The Skeptical Environmentalist: Measuring the Real State of the World, Cambridge: Cambridge University Press

Mason, S. and Joubert, A., 1997, 'Simulated changes in extreme rainfall over southern Africa', International Journal of Climatology, Vol 17: 291-301

Maxwell, S. and Slater, R., 2003, 'Food policy old and new', Briefing Paper, London: Overseas Development Institute, November

Mendelsohn, R., Dinar, A. and Delfelt, A., 2000a, 'Climate change impacts on African agriculture,' mimeo, Centre for Environmental Economics and Policy in Africa

Mendelsohn, R., Morrison, W., Schlesinger, M.E., Andronova, N.G. 2000b, 'Country specific market impacts from climate change', Climatic Change, Vol 45: 553-69

O'Brien, K. and Vogel, C., 2003, Coping with Climate Variability: The Use of Seasonal Climate Forecasts in Southern Africa, Studies in Environmental Policy and Practice, Hampshire: Ashgate

Ogunseitan, O.A., 2003, 'Framing environmental change in Africa: cross-scale institutional constraints on progressing from rhetoric to action against vulnerability', Global Environmental Change, Vol 13: 101-11

Parry, M., 2002, 'Scenarios for climate impact and adaptation assessment', Global Environmental Change, Vol 12: 149-53
Richard, Y., Fauchereau, N., Poccard, I., Rouault, M. and Trzaska, S., 2001, '20th century droughts in southern Africa: spatial and temporal variability, teleconnections with oceanic and atmospheric conditions', International Journal of Climatology, Vol 24 No 7: 873-85

Rosenzweig, C. and Hillel, D., 1998, Climate Change and the Global Harvest: Potential Impacts of the Greenhouse Effect on Agriculture, New York: Oxford University Press

Sachs, J.D., 2005, The End of Poverty, Economic Possibilities for Our Time, New York: The Penguin Press

SafMa, 2004, 'The Southern African Millennium Ecosystem Assessment', Integrated Report, Nature Supporting People, Cape Town: Council for Scientific and Industrial Research (CSIR)

Sokona, Y. and Denton, F., 2001, 'Climate change impacts: can Africa cope with the challenges?', Climate Policy, Vol 1 No 1: 117-23

Thomas, C.D., Cameron, A., Green, R.E., Bakkenes, M., Beaumont, L.J., Collingham, Y.C., Erasmus, B.F.N., Ferreira de Siqueira, M., Grainger, A., Hannah, L., Hughes, L., Huntley, B., van Jaarsveld, A.S., Midgley, G.F., Miles, L., OrtegaHuerta, M.A., Townsend Peterson, A., Phillips, O.L., Williams, S.E., 2004, 'Extinction risk from climate change', Letters to Nature, Vol 427: 145-8

Washington, R.W., Harrison, M. and Conway, D., 2004, 'African Climate Report', report commissioned by the UK Government to review African climate science, policy and options for action, London: Department of Environment, Food and Rural Affairs

Weatherspoon, D.D. and Reardon, T., 2003, 'The rise of supermarkets in Africa: implications for agrifood systems and the rural poor', Development Policy Review, Vol 21 No 3: 333-55 